\title{
BMJ Open Video decision aids to assist with advance care planning: a systematic review and meta-analysis
}

\author{
Ashu Jain, ${ }^{1}$ Sophie Corriveau, ${ }^{2}$ Kathleen Quinn, ${ }^{3}$ Amanda Gardhouse, ${ }^{4}$ \\ Daniel Brandt Vegas, ${ }^{5}$ John J You ${ }^{6}$
}

To cite: Jain A, Corriveau S, Quinn $\mathrm{K}$, et al. Video decision aids to assist with advance care planning: a systematic review and meta-analysis. BMJ Open 2015;5:e007491. doi:10.1136/bmjopen-2014007491

- Prepublication history and additional material is available. To view please visit the journal (http://dx.doi.org/ 10.1136/bmjopen-2014007491).

Received 18 December 2014 Revised 3 May 2015

Accepted 3 June 2015

CrossMark

For numbered affiliations see end of article.

Correspondence to

Dr John J You;

jyou@mcmaster.ca

\section{ABSTRACT}

Objective: Advance care planning (ACP) can result in end-of-life care that is more congruent with patients' values and preferences. There is increasing interest in video decision aids to assist with ACP. The objective of this study was to evaluate the impact of video decision aids on patients' preferences regarding life-sustaining treatments (primary outcome).

Design: Systematic review and meta-analysis of randomised controlled trials.

Data sources: MEDLINE, EMBASE, PsycInfo, CINAHL, AMED and CENTRAL, between 1980 and February 2014, and correspondence with authors.

Eligibility criteria for selecting studies:

Randomised controlled trials of adult patients that compared a video decision aid to a non-video-based intervention to assist with choices about use of lifesustaining treatments and reported at least one ACPrelated outcome.

Data extraction: Reviewers worked independently and in pairs to screen potentially eligible articles, and to extract data regarding risk of bias, population, intervention, comparator and outcomes. Reviewers assessed quality of evidence (confidence in effect estimates) for each outcome using the Grading of Recommendations Assessment, Development and Evaluation framework.

Results: 10 trials enrolling 2220 patients were included. Low-quality evidence suggests that patients who use a video decision aid are less likely to indicate a preference for cardiopulmonary resuscitation (pooled risk ratio, 0.50 (95\% Cl 0.27 to 0.95$) ;\left.\right|^{2}=65 \%$ ). Moderate-quality evidence suggests that video decision aids result in greater knowledge related to ACP (standardised mean difference, $0.58(95 \% \mathrm{Cl} 0.38$ to $0.77) ; 1^{2}=0 \%$ ). No study reported on the congruence of end-of-life treatments with patients' wishes. No study evaluated the effect of video decision aids when integrated into clinical care.

Conclusions: Video decision aids may improve some ACP-related outcomes. Before recommending their use in clinical practice, more evidence is needed to confirm these findings and to evaluate the impact of video decision aids when integrated into patient care.

\section{INTRODUCTION}

Individuals will often face important decisions about their care as they approach the

\section{Strengths and limitations of this study}

- This systematic review provides a synthesis of the available evidence from 10 randomised controlled trials about the impact of video decision aids to assist with advance care planning (ACP).

- There is low-to-moderate quality evidence suggesting that video decision aids lead to greater knowledge related to ACP and preferences for less aggressive care at end of life.

- To date, no studies have examined the effect of ACP video decision aids on congruence of end-of-life treatment with patients' preferences, nor have they evaluated their impact when integrated into clinical care.

end of life, but many will lose the capacity to make these decisions for themselves. ${ }^{1}$ Advance care planning (ACP) offers a solution to this problem. ACP can be defined as a communication and decision-making process that allows individuals to clarify their values and preferences for future care, and enables them to communicate their wishes to loved ones, surrogate decisionmakers and healthcare providers. ${ }^{2}$ ACP may increase the likelihood that patients' wishes are known and respected at end of life, and may improve quality of life for patients and reduce caregiver regret during bereavement. ${ }^{3-5}$ Since ACP has potential benefits, leading medical organisations have called for greater uptake of ACP to enhance the quality of end-of-life care. ${ }^{6} 7$

Decision aids can increase patients' knowledge of treatment options and outcomes, help patients to clarify their own values and increase patients' participation in medical decision-making. ${ }^{8}$ As such, they may help increase the quality of ACP; however, a recent overview of decision aids for ACP concluded that, while many decision aids are widely available, there is need for greater evaluation of their effectiveness. ${ }^{9}$ Video decision aids for ACP have garnered appreciable interest in the academic community, among 
health policymakers and in the popular press. ${ }^{10-12}$ Videos may assist with ACP because they can dynamically depict diminishing health states and the nature of different treatment options, and may help individuals to become more informed and confident about their preferences for care at end of life. We conducted a systematic review to determine, among adult patients, the impact of video decision aids on patients' preferences for life-sustaining treatments and other ACP-related outcomes, compared with non-video-based interventions.

\section{METHODS}

\section{Data sources and searches}

A medical librarian searched MEDLINE, EMBASE, PsycInfo, CINAHL, the Allied and Complementary Medicine Database (AMED), and the Cochrane Central Register of Controlled Trials (CENTRAL), using terms such as "advance care planning", "video", and "end of life", for relevant articles published in any language between 1980 and February 2014 (see web appendix for detailed search strategy). The systematic review was not registered with a central database.

\section{Study selection}

Articles were eligible for inclusion if they reported original data from a randomised controlled trial (RCT) that met each of the following criteria: (1) enrolled adult patients (age 18 years or older) in an inpatient or outpatient setting; (2) included an arm evaluating an ACP video decision aid to assist with choices about future use of life-sustaining treatments (eg, cardiopulmonary resuscitation (CPR), intensive care unit admission); (3) included a comparator arm with no ACP video decision aid component (eg, sham video, traditional methods of decision support such as verbal description, pamphlets, usual care, or no discussion) and (4) reported data on at least one outcome of interest. The primary outcome of interest for this review was patients' preferences regarding the use of life-sustaining treatments. We selected this primary outcome because patients are often misinformed about the nature of lifesustaining treatments, ${ }^{13}$ such as CPR, and thus hypothesised that video decision aids aimed at assisting with choices about life-sustaining treatments would have an effect on patients' preferences. ${ }^{14}$ Secondary outcomes of interest were: patients' knowledge related to ACP (including knowledge about life-sustaining treatments), patients' confidence in any decision made about future use of life-sustaining treatments, completion of an advance directive (as defined by the authors of the individual studies), actual use of life-sustaining treatments at end of life, whether the use of life-sustaining treatments at end of life was congruent with patients' prior expressed wishes, health resource use at end of life and, for patients allocated to the video intervention arm, patients' comfort watching the video.
Using web-based systematic review software (DistillerSR, Ottawa, Canada), paired reviewers (AJ and $\mathrm{KQ}, \mathrm{AG}$ and $\mathrm{SC}$ ) independently conducted screening as: first, title and abstracts, followed by full texts of articles for which either reviewer judged that titles or abstracts appeared potentially eligible. Any disagreements between reviewers regarding final eligibility at full-text review were resolved by discussion and additional consultation with a third reviewer (JJY), when necessary.

\section{Data extraction and quality assessment}

Two pairs of reviewers (AJ and JJY, DBV and JJY) assessed the methodological quality of eligible studies and extracted data regarding the patient population, interventions, comparators and outcomes, using a standardised, pilot-tested data extraction form developed by the investigators for this review. We assessed risk of bias using Cochrane systematic review guidelines, which include an assessment of random sequence generation, allocation concealment, blinding (of patients, healthcare providers, outcome assessors and analysts) and loss to follow-up. ${ }^{15}$ Any discrepancies during data extraction were resolved by discussion between reviewers. We contacted authors if we required clarification of issues related to the conduct of the trial or missing data.

For each outcome of interest, we assessed the quality of evidence, defined as confidence in the estimate of effect, using the Grading of Recommendations Assessment, Development and Evaluation (GRADE) framework. In this approach, RCTs begin as high-quality evidence, but may be rated down due to limitations related to risk of bias, indirectness, inconsistency (ie, heterogeneity), imprecision and publication bias. ${ }^{16}$

\section{Data synthesis and analysis}

We used Cohen's $\kappa$ to assess chance-corrected inter-rater agreement of reviewers' decisions about potential eligibility of articles at title and abstract screening, and about the eligibility of articles at full-text review. For each outcome of interest, when possible, data were pooled to obtain a summary estimate of effect. When data for a given outcome measure were collected at more than one follow-up time point, we used data from the longest available follow-up time. When outcome data were missing, we used a complete case analysis (ie, participants with missing outcome data were excluded from the analysis if these data could not be obtained from authors). For the primary outcome of patients' preferences for use of life-sustaining treatments, four studies elicited preferences in a dichotomous fashion (CPR vs no CPR), ${ }^{17-20}$ and three studies elicited preferences using three response options: life-prolonging care (includes CPR), limited care (does not include CPR), or comfort care (does not include CPR). ${ }^{21-23}$ In our pooled analyses, we treated patient preferences from the latter three studies as a dichotomous outcome: CPR (life-prolonging care), or no CPR (limited care or comfort care). 


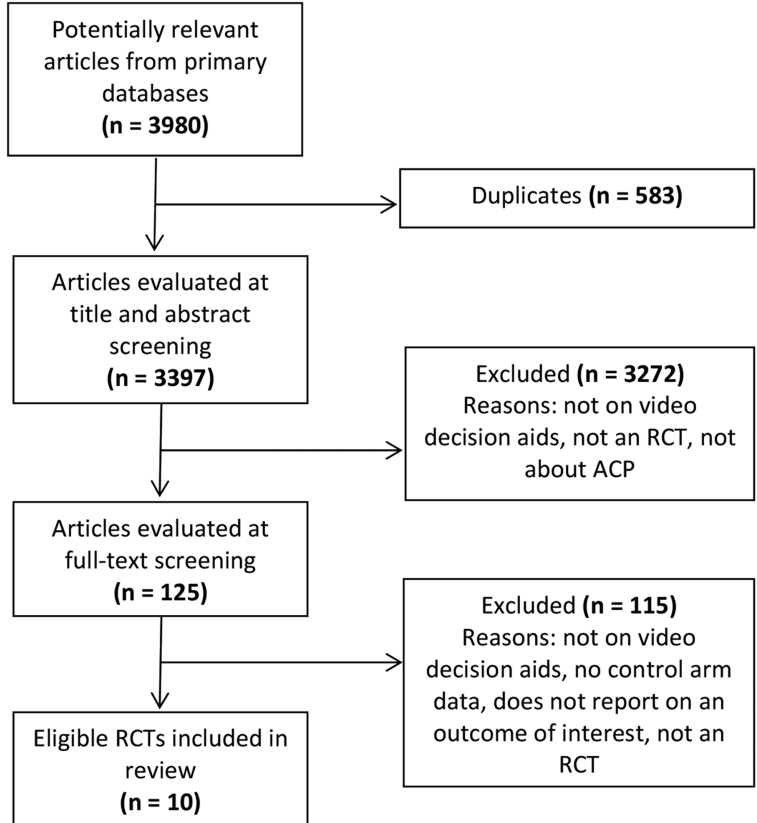

Figure 1 Summary of article selection (ACP, advance care planning; $\mathrm{RCT}$, randomised controlled trial).

For dichotomous outcome data, we used random-effects models (using the method of DerSimonian and Laird) to calculate pooled risk ratios and $95 \%$ CIs. For continuous outcome data, we used random-effects models to calculate a pooled standardised mean difference and 95\% CI. Heterogeneity was assessed using a $\chi^{2}$ test for heterogeneity and the $\mathrm{I}^{2}$ statistic. Analyses were performed using Review Manager (RevMan) V.5.2 (Cophenhagen, The Nordic Cochrane Centre: The Cochrane Collaboration, 2012). We considered a $p$ value of 0.05 to be statistically significant.

\section{RESULTS}

Of 3980 citations identified from primary electronic databases, 583 were duplicates, leaving 3397 original publications. Of these, 125 were deemed potentially eligible $(\kappa=0.29)$ and underwent full-text screening. Of these 125 full-text articles, 10 RCTs were eligible for our review ( $\kappa=0.48$; figure 1 ). ${ }^{17-26}$ Six of the studies were conducted by the same group of investigators and published within the past 5 years. ${ }^{18-23}$ The other four studies were published in the late 1990s by four different research groups. ${ }^{17}{ }^{24-26}$ Of the six authors we contacted, we received additional information from four $(67 \%)$.

The 10 eligible RCTs enrolled a total of 2220 patients, 1092 of whom were allocated to the video arm and 1128 of whom were allocated to the control arm. Patients were most often recruited from outpatient primary care or oncology settings (all in the USA) and had a mean age between 51 and 81 years (table 1). Videos used in the different studies were between 2 and $15 \mathrm{~min}$ in length, with some videos focusing on the creation of advance directives, ${ }^{17}$ 24-26 some including a visual description of advanced dementia, ${ }^{22}{ }^{23}$ some focusing on the delineation of three options for medical care (life-prolonging care, limited medical care and comfort care), ${ }^{182123}$ and some focusing on a description of CPR and the likelihood of its success in patients with advanced cancer ${ }^{19}{ }^{20}$ (table 1 ). In 2 of the 10 trials, study procedures included a step that provided an opportunity for patients to engage in some form of discussion with a healthcare professional (their own physician, ${ }^{17}$ or a study nurse ${ }^{26}$ ) after they were exposed to the study intervention (video or control). No study evaluated the impact of a video decision aid when integrated into clinical workflow.

Risk of bias for the 10 included trials is summarised in figure 2. Two studies adequately concealed allocation. ${ }^{20} 26$ The remaining eight studies either: did not conceal allocation $(\mathrm{n}=1) ;{ }^{17}$ used envelopes, but without procedures in place to enforce or audit adherence to the allocation sequence $(n=5) ;^{18} 1921-23$ or did not report whether allocation was concealed $(\mathrm{n}=2) .{ }^{24}{ }^{25}$ In six of the studies, ${ }^{17} 18$ 21-23 25 outcome assessors were not blinded. Duration of follow-up was variable across the eligible studies. Seven studies reported data on participants' preferences for use of life-sustaining treatments immediately after receiving the study intervention, ${ }^{17-23}$ whereas some studies also elicited preferences after $2-4$ weeks follow-up ( 1 study), ${ }^{17}$ or 6-8 weeks follow-up (2 studies). ${ }^{19} \quad 22$ Completion of advance directive completion was assessed at 2-4 weeks in one study, ${ }^{17}$ at 3 months in two studies ${ }^{25} 26$ and at 6 months in another study. ${ }^{20}$ Loss to follow-up, that is, the percentage of participants with missing outcome data, was low $(0-11 \%)$ in 7 of the 10 included studies, whereas the studies by Siegert et $a l^{24}$ Yamada et $a l^{17}$ and Volandes et $a l^{19}$ had higher rates of $14 \%, 23 \%$ and $55 \%$ loss to follow-up (missing outcome data), respectively.

\section{Patient preferences for use of life-sustaining treatments}

Seven studies reported on patient preferences for use of life-sustaining treatments. ${ }^{17-23}$ Low-quality evidence (rated down for risk of bias and inconsistency) suggests that, after receiving the video intervention, patients were less likely to indicate a preference for CPR compared with those in the control arm (risk ratio, 0.50 (95\% CI 0.27 to 0.95$)$; $\mathrm{I}^{2}=65 \%$; heterogeneity $\mathrm{p}=0.01$; figure 3 ). The substantial heterogeneity across studies may have been driven by the study by Yamada $e t a l,{ }^{17}$ which was published over a decade earlier than the six other RCTs that reported on this outcome, and had a much higher proportion of patients indicating a preference for CPR than the other studies.

\section{Knowledge related to ACP}

One study found that a video decision aid increased the proportion of patients with correct responses to questions about the interventions included with CPR (intravenous fluid, endotracheal intubation, mechanical ventilation, defibrillation), the likely outcomes of CPR and about advance directives; however, with the 


\begin{tabular}{|c|c|c|c|c|c|c|c|}
\hline \multirow[b]{2}{*}{ Study } & \multirow[b]{2}{*}{ Population } & \multicolumn{2}{|l|}{ Video group } & \multicolumn{2}{|l|}{ Control group } & \multirow[b]{2}{*}{ Video } & \multirow[b]{2}{*}{ Control } \\
\hline & & $\begin{array}{l}\text { Participants, } \\
\text { n }\end{array}$ & $\begin{array}{l}\text { Mean } \\
\text { age } \\
\text { (years) }\end{array}$ & $\begin{array}{l}\text { Participants, } \\
\text { n }\end{array}$ & $\begin{array}{l}\text { Mean } \\
\text { age } \\
\text { (years) }\end{array}$ & & \\
\hline $\begin{array}{l}\text { Epstein } \\
\text { et afo }\end{array}$ & $\begin{array}{l}\text { Patients with progressive } \\
\text { pancreatic or hepatobiliary } \\
\text { cancer from outpatient } \\
\text { oncology clinics in } \\
\text { New York City }\end{array}$ & 30 & 65 & 26 & 66 & $\begin{array}{l}3 \text { min video providing a narrative } \\
\text { description of CPR, and likelihood } \\
\text { of its success in patients with } \\
\text { advanced cancer. Images include } \\
\text { simulated CPR, endotracheal } \\
\text { intubation, and a sedated patient } \\
\text { being mechanically ventilated in an } \\
\text { ICU }\end{array}$ & $\begin{array}{l}\text { Verbal description of CPR by } \\
\text { research staff (same script as } \\
\text { video arm) }\end{array}$ \\
\hline $\begin{array}{l}\text { Volandes } \\
\text { et } a l^{19}\end{array}$ & $\begin{array}{l}\text { Patients with advanced } \\
\text { cancer from outpatient } \\
\text { clinics at } 4 \text { oncology } \\
\text { centers in Boston, } \\
\text { New York City and } \\
\text { Nashville }\end{array}$ & 70 & 63 & 80 & 62 & $\begin{array}{l}\text { Verbal description by research staff } \\
\text { of CPR, and likelihood of its } \\
\text { success in patients with advanced } \\
\text { cancer, followed by a } 3 \text { min video. } \\
\text { The video repeats the same } \\
\text { narrative description of CPR and } \\
\text { included images of simulated CPR } \\
\text { and endotracheal intubation, and a } \\
\text { ventilated patient receiving } \\
\text { intravenous medicines }\end{array}$ & $\begin{array}{l}\text { Verbal description of CPR by } \\
\text { research staff (same script as } \\
\text { video arm) }\end{array}$ \\
\hline $\begin{array}{l}\text { Volandes } \\
\text { et } a^{R^{1}}\end{array}$ & $\begin{array}{l}2 \text { skilled nursing facilities } \\
\text { in Boston }\end{array}$ & 50 & 79 & 51 & 76 & $\begin{array}{l}6 \text { min video describing and } \\
\text { depicting } 3 \text { options for care } \\
\text { (life-prolonging care, limited medical } \\
\text { care, comfort care) }\end{array}$ & $\begin{array}{l}\text { Verbal description of the same } 3 \\
\text { options for care as the video }\end{array}$ \\
\hline $\begin{array}{l}\text { Volandes } \\
\text { et } a^{R^{3}}\end{array}$ & $\begin{array}{l}\text { Primary care clinic in rural } \\
\text { Louisiana }\end{array}$ & 33 & 73 & 43 & 75 & $\begin{array}{l}\text { Verbal description of advanced } \\
\text { dementia and } 3 \text { options for care } \\
\text { (life-prolonging care, limited medical } \\
\text { care, comfort care), followed by a } \\
6 \text { min video. The video describes } \\
\text { and depicts features of advanced } \\
\text { dementia and the } 3 \text { options for care }\end{array}$ & $\begin{array}{l}\text { Verbal description of advanced } \\
\text { dementia and } 3 \text { options for care } \\
\text { (same script as video arm) }\end{array}$ \\
\hline $\begin{array}{l}\text { El-Jawahri } \\
\text { et }\left.a\right|^{18}\end{array}$ & $\begin{array}{l}\text { Patients with malignant } \\
\text { glioma from outpatient } \\
\text { oncology clinics in Boston }\end{array}$ & 23 & 56 & 27 & 51 & $\begin{array}{l}\text { Verbal description of } 3 \text { options for } \\
\text { care (life-prolonging care, limited } \\
\text { medical care, comfort care), } \\
\text { followed by } 6 \text { min video. The video } \\
\text { describes and depicts } 3 \text { options for } \\
\text { care }\end{array}$ & $\begin{array}{l}\text { Verbal description of } 3 \text { options } \\
\text { for care (same script as video } \\
\text { arm) }\end{array}$ \\
\hline $\begin{array}{l}\text { Volandes } \\
\text { et } a^{R^{2}}\end{array}$ & $\begin{array}{l}4 \text { primary care clinics } \\
\text { affiliated with teaching } \\
\text { hospitals in Boston }\end{array}$ & 94 & 75 & 106 & 75 & $\begin{array}{l}\text { Verbal description of principal } \\
\text { features of advanced dementia, } \\
\text { followed by } 2 \text { min video. The video }\end{array}$ & $\begin{array}{l}\text { Verbal description of principal } \\
\text { features of advanced dementia } \\
\text { (same script as video arm) }\end{array}$ \\
\hline
\end{tabular}




\begin{tabular}{|c|c|c|c|c|c|c|c|}
\hline \multirow[b]{2}{*}{ Study } & \multirow[b]{2}{*}{ Population } & \multicolumn{2}{|l|}{ Video group } & \multicolumn{2}{|c|}{ Control group } & \multirow[b]{2}{*}{ Video } & \multirow[b]{2}{*}{ Control } \\
\hline & & $\begin{array}{l}\text { Participants, } \\
\text { n }\end{array}$ & $\begin{array}{l}\text { Mean } \\
\text { age } \\
\text { (years) }\end{array}$ & $\begin{array}{l}\text { Participants, } \\
\mathrm{n}\end{array}$ & $\begin{array}{l}\text { Mean } \\
\text { age } \\
\text { (years) }\end{array}$ & & \\
\hline & & & & & & $\begin{array}{l}\text { depicts the principal features of } \\
\text { advanced dementia }\end{array}$ & \\
\hline $\begin{array}{l}\text { Brown } \\
\text { et } a^{26}\end{array}$ & $\begin{array}{l}\text { Primary care clinic in } \\
\text { Colorado }\end{array}$ & 619 & 81 & 628 & 81 & $\begin{array}{l}\text { Mailed package, including a } \\
\text { videotape (Peace of Mind: } \text { Advance } \\
\text { Directives), of } 9 \text { patient or family } \\
\text { member interviews, plus the same } \\
\text { printed materials as control }\end{array}$ & $\begin{array}{l}\text { Mailed package of printed } \\
\text { materials including an } \\
\text { educational pamphlet (You and } \\
\text { Your Choices), a Colorado } \\
\text { Advance Directive Guide, and } \\
\text { forms for execution of a durable } \\
\text { power of attorney for healthcare, } \\
\text { a living will, and a CPR directive }\end{array}$ \\
\hline $\begin{array}{l}\text { Yamada } \\
\text { et } a l^{17}\end{array}$ & $\begin{array}{l}\text { General internal medicine } \\
\text { clinic of a Veterans Affairs } \\
\text { Medical Center in } \\
\text { Michigan }\end{array}$ & 62 & 74 & 55 & 74 & $\begin{array}{l}10 \text { min video about advance } \\
\text { directives (Advance Directives: } \\
\text { Guaranteeing Your Health Care } \\
\text { Rights), a handout about CPR and } \\
\text { its outcomes, plus the same } \\
\text { handout as control }\end{array}$ & $\begin{array}{l}\text { Handout describing advance } \\
\text { directives only (ie, not CPR) }\end{array}$ \\
\hline $\begin{array}{l}\text { Landry } \\
\text { et } a f^{5}\end{array}$ & $\begin{array}{l}\text { General internal medicine } \\
\text { clinic of a military teaching } \\
\text { hospital in Maryland }\end{array}$ & 95 & 61 & 92 & 63 & $\begin{array}{l}15 \text { min video detailing advance } \\
\text { directives. The video was part of a } \\
60 \text { min seminar, which also included } \\
\text { a didactic presentation about } \\
\text { advance directives, interactive } \\
\text { question and answer session and } \\
\text { review of a recommended advance } \\
\text { directive form }\end{array}$ & $\begin{array}{l}\text { Mailed advance directive form } \\
\text { and information pamphlet }\end{array}$ \\
\hline $\begin{array}{l}\text { Siegert } \\
\text { et } a R^{4}\end{array}$ & $\begin{array}{l}\text { Nursing home care unit of } \\
\text { a Veterans Affairs Medical } \\
\text { Center in North Carolina }\end{array}$ & 16 & 69 & 20 & 69 & $\begin{array}{l}14 \text { min video (The Right to Die ... } \\
\text { The Choice is Yours) about } \\
\text { advance directives }\end{array}$ & $\begin{array}{l}25 \text { min sham video (I Am Joe's } \\
\text { Heart) about heart disease } \\
\text { prevention strategies }\end{array}$ \\
\hline
\end{tabular}




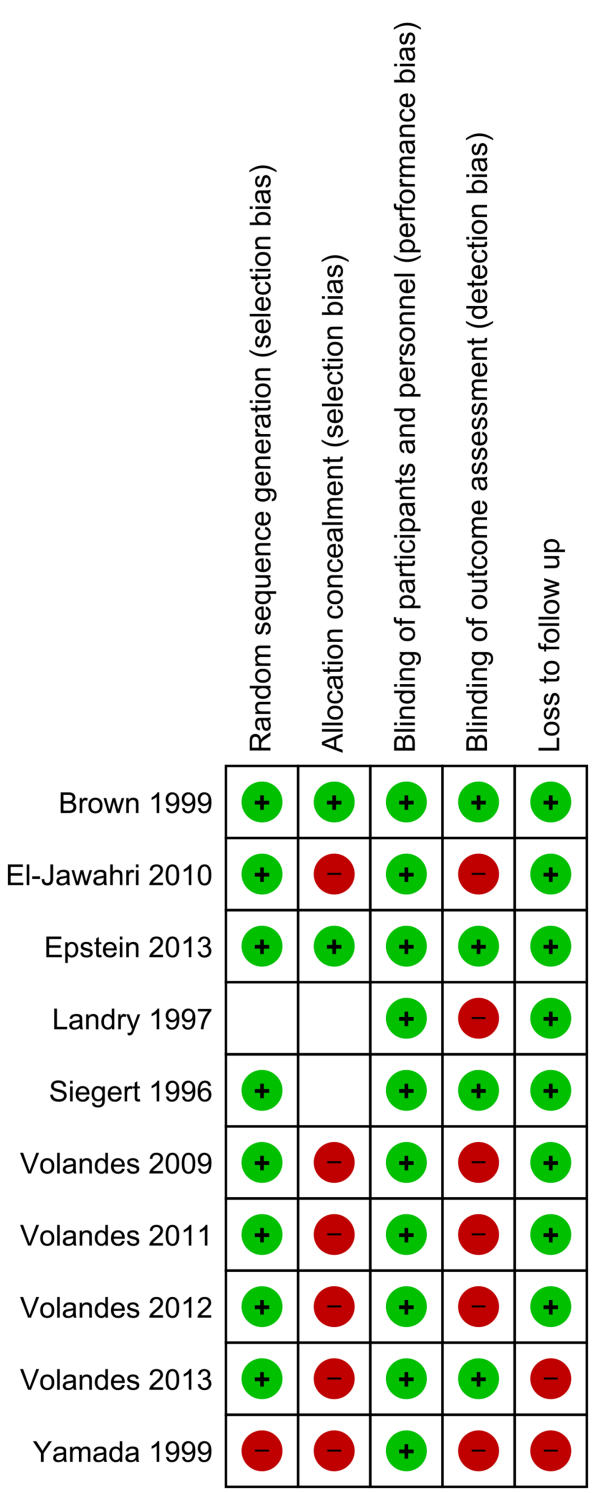

Figure 2 Risk of bias in eligible studies. Review authors' judgements about each risk of bias item for each included study. Green circles=low risk of bias; red circles=high risk of bias; empty boxes=unclear risk of bias.

exception of increased knowledge about advance directives, other estimates of effect were imprecise and not statistically significant. ${ }^{17}$

Five studies reported on knowledge related to different aspects of ACP using a variety of measurement scales. $^{18-20} 2224$ One study assessed knowledge about living wills and CPR, ${ }^{24}$ another study assessed knowledge about advanced dementia, ${ }^{22}$ and three studies assessed knowledge about CPR. ${ }^{18-20}$ One of the latter studies ${ }^{20}$ Epstein et al did not report sufficient detail to allow inclusion in our pooled analysis. In the four studies with poolable data, ${ }^{18} 1922{ }^{24}$ there was moderate-quality evidence (rated down for risk of bias) that video decision aids resulted in greater knowledge scores compared with control (standardised mean difference, 0.58 (95\% CI 0.39 to 0.77$) ; \mathrm{I}^{2}=0 \%$; heterogeneity $\mathrm{p}=0.99$; figure 4 ).

\section{Completion of advance directives}

Four trials reported data on completion of advance directives. ${ }^{17202526}$ One study defined advance directives as 'any document that instructed caregivers on details of future care', ${ }^{20}$ another study provided no definition, ${ }^{17}$ and two other studies reported data on the completion of living wills as well as durable powers of attorney for healthcare. For the latter two studies, we used the data related to the completion of living wills. ${ }^{25}{ }^{26}$ Low-quality evidence (rated down for risk of bias and imprecision) suggests there may be a small effect of video decision aids on this outcome, but with a wide $95 \%$ CI including no effect (risk ratio, 1.11 (95\% CI 0.85 to 1.46$) ; \mathrm{I}^{2}=44 \%$; heterogeneity $\mathrm{p}=0.15$; figure 5 ).

\section{Other outcomes}

El-Jawahri and colleagues found that a video decision aid led to greater confidence in patients' decisions about future use of life-sustaining treatments compared with controls, as measured using the uncertainty subscale of the Decisional Conflict Scale $(0=$ complete uncertainty, $15=$ perfect certainty) ${ }^{27}$ (mean scores 13.7 in video group vs 11.5 in control group, $\mathrm{p}=0.002$ ). In five of the studies, patients in the video arm were asked to rate their comfort with watching the video. ${ }^{18-22}$ The majority of patients indicated that they were very comfortable $\left(83 \%,{ }^{18} 69 \%{ }^{20}\right)$, or at least somewhat comfortable $\left(85 \%,{ }^{22} 90 \%,{ }^{21} 93 \%{ }^{19}\right)$, watching the video.

One study included in this review, a pilot RCT, reported data on use of life-sustaining treatments and resource use at the end of life, and found that a video decision aid was not associated with a statistically significant difference in hospital admissions at 6-month follow-up (or until time of death), or hospital length of stay. ${ }^{20}$ However, this study may not have been adequately powered to show a difference in these outcomes and does not exclude the possibility of an effect. In this study, there were no intensive care unit admissions during 6-month follow-up for the 30 individuals randomised to the video arm, and three intensive care unit admissions in the 26 individuals randomised to control during 6-month follow-up there was one episode of CPR or mechanical ventilation in the video arm and three episodes of CPR or mechanical ventilation in the control arm. No studies reported whether the use of video decision aids affected the congruence of lifesustaining treatments at end of life with patients' prior expressed wishes.

\section{DISCUSSION}

In this systematic review of RCTs, we found low-to-moderate quality evidence suggesting that video decision aids lead to greater knowledge related to ACP and preferences for less aggressive care at end of life. Studies of ACP video decision aids, to date, provide little or no data on other important outcomes related to ACP, such as confidence in decision-making, the actual use of 


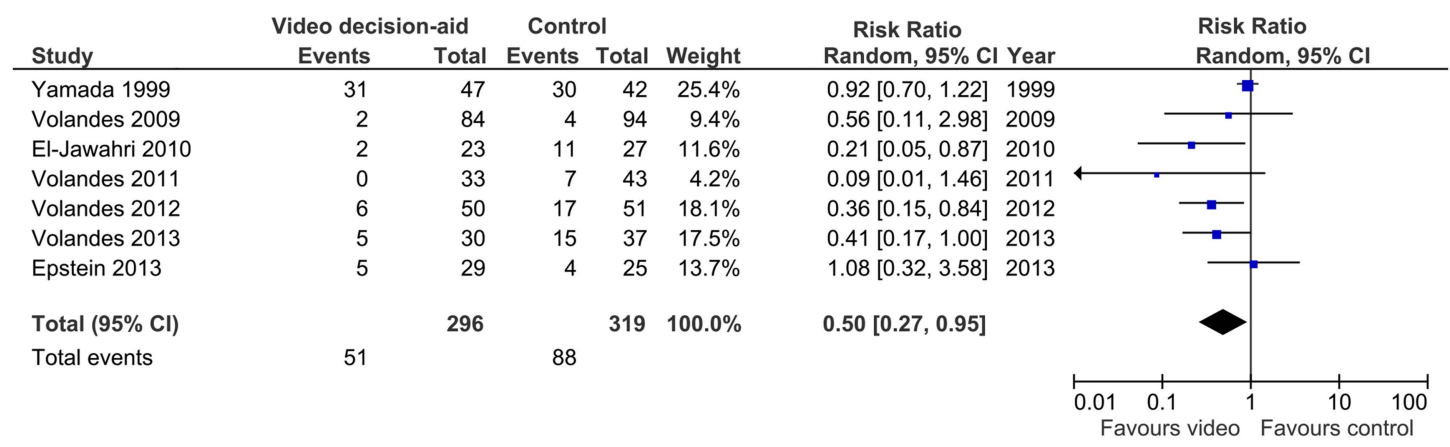

Figure 3 Effect of video decision aids on patient preferences for cardiopulmonary resuscitation. Effect of the video intervention in individual studies and the pooled effect across studies from a random-effects model are expressed as risk ratios and $95 \%$ Cls. A risk ratio less than 1.0 means that patients in the video arm were less likely to prefer cardiopulmonary resuscitation compared with those in the control arm.

life-sustaining treatments at end of life, or the congruence of end-of-life treatments with patients' wishes. Although an important aspect of ACP is to clarify patients' preferences for life-sustaining treatments, including CPR, ACP involves several other important processes. In contemporary thinking, the focus of ACP is shifting away from making decisions about future treatment choices and putting more emphasis on the need to prepare future surrogate decisionmakers for 'in-the-moment' decision-making. ${ }^{2}$ In this way, ACP can be seen as a broader set of behaviours, including: choosing a surrogate decisionmaker, deciding what matters most in life (clarifying values and, in some cases, future wishes for treatments such as CPR), and communicating these values and wishes to surrogate decisionmakers to better prepare them to engage in future 'in-the-moment' medical decision-making when the patient becomes incapable. We did not find any RCTs of video decision aids that examined ACP from this perspective. However, web-based decision aids have recently been designed to change these different behaviours related to $\mathrm{ACP}^{28-30}$

Strengths of our review include adherence to the Preferred Reporting Items for Systematic Reviews and Meta-Analyses (PRISMA) standards for conduct and reporting of a systematic review, including a comprehensive literature search and a systematic approach for categorising confidence in the effect estimates (GRADE)..$^{15} \quad 16 \quad 31$
Our systematic review also has limitations. First, we restricted our search strategy to articles published in 1980 or later, and it is possible that we missed older, relevant articles. However, none of the trials included in our review were published before 1996, and the concepts of advance directives and ACP did not gain widespread attention until the 1990s (eg, after the introduction of the US Patient Self-Determination Act in 1990). Second, for studies with missing outcome data, we did not use imputation methods. By including only patients with non-missing data (complete case analysis) in our meta-analyses, our resultant estimates of effect could be biased if patients lost to follow-up were systematically different in ways that were related to our outcomes of interest (eg, if they were systematically more or less likely to prefer CPR). Finally, our review also has limitations due to the limitations of the studies included in our review. First, there are differences across the eligible RCTs. The studies were clustered into a group of more recent studies conducted by the same group of investigators (Volandes $e t a l$ ) and a group of studies published in the 1990s. Our intention for this systematic review was to be comprehensive and inclusive of the entire body of RCTs regarding video decision aids for ACP, but we acknowledge that the older studies may have differed from more recent ones in several important ways. For instance, the focus of the video interventions in the 1990s was on the creation of advance directives, whereas

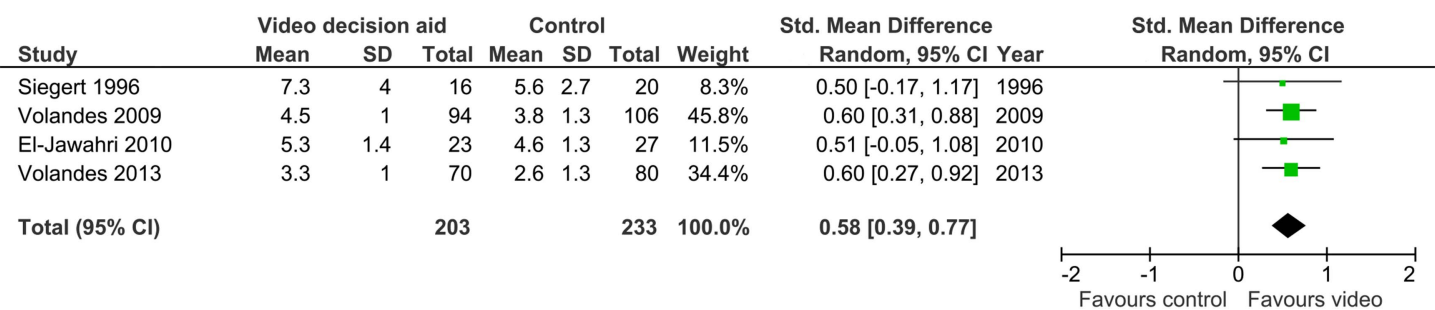

Figure 4 Effect of video decision aids on knowledge related to advance care planning. Effect of the video intervention in individual studies and the pooled effect across studies from a random-effects model are expressed as standardised mean differences and $95 \% \mathrm{Cls}$. A standardised mean difference greater than zero means that knowledge about advance care planning was greater for patients in the video arm compared with those in the control arm. 


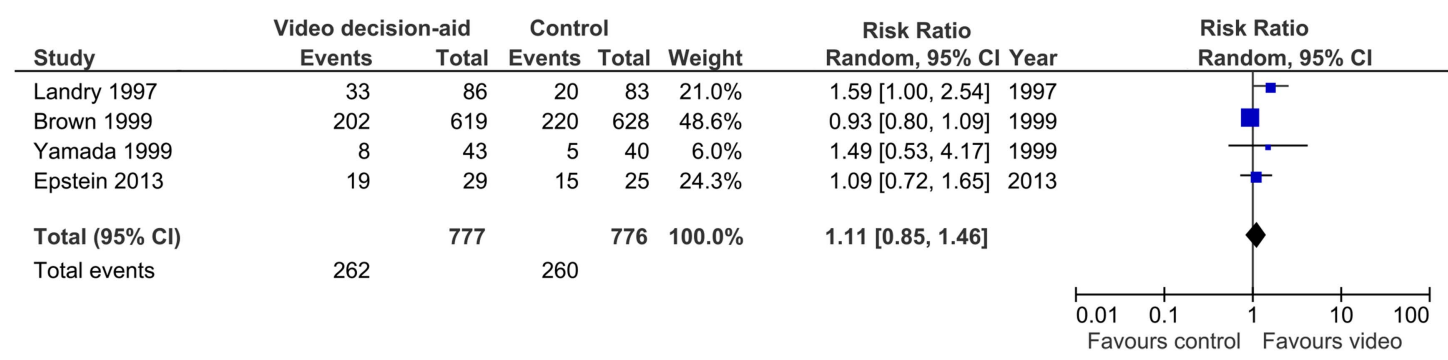

Figure 5 Effect of video decision aids on completion of advance directives. Effect of the video intervention in individual studies and the pooled effect across studies from a random-effects model are expressed as risk ratios and $95 \% \mathrm{Cls}$. A risk ratio greater than 1.0 means that patients in the video arm were more likely to complete an advance directive compared with those in the control arm.

more recent video interventions have focused on clarifying preferences for goals of care (life-prolonging care, limited care, or comfort care) or CPR. Eligible studies also elicited preferences in different ways and it is possible that framing of response options as a binary choice (CPR vs no CPR) or as choice between three options (life-prolonging care, limited care, or comfort care) may have influenced participants' stated preferences. Another limitation of the existing studies is that they report little or no data on other outcomes relevant to ACP, such as confidence in decision-making, resource use at end of life and congruence of end-of-life care with patient wishes. This narrower focus of the existing trials on the elicitation of treatment preferences or creation of advance directives, rather than the broader range of activities that are part of ACP, and the fact that all the included studies were carried out in the USA, raise questions about the applicability of the available evidence in other countries and in the context of changing definitions of ACP.

Butler et at recently completed a technical brief, commissioned by the Agency for Healthcare Research and Quality in the USA, to provide an overview of a broad range of ACP decision aids for adults. The report provides a state-of-the-art review of the field but, because it used technical brief methodology, it did not include a synthesis or meta-analysis of outcomes, ratings of risk of bias or assessment of the quality of evidence. It also did not include several RCTs of video decision aids for ACP that were identified in our review, including several recent trials. ${ }^{18-21}$ Our review provides complementary and contemporary data on a well-specified clinical question (among adult patients, do video decision aids have an effect on outcomes related to ACP when compared with non-video-based interventions?), including assessments of risk of bias, quality of evidence and a synthesis of outcomes.

We found a large and statistically significant effect of video decision aids on patients' preferences for CPR, with those exposed to the video intervention being half as likely to prefer CPR as those exposed to a non-video-based intervention. It is possible that some of this effect is a result of bias introduced by incomplete concealment of allocation or unblinded outcome assessment, as opposed to a true effect of the video decision aid. Future trials could overcome these methodological limitations by using centralised telephone or web-based randomisation to preserve allocation concealment and blinding the outcome assessors to allocation. ${ }^{32}$ It is also possible that some of the observed effect is attributable to the 'dose' of information received in the intervention arms: four of the seven studies that reported on patients' preferences presented the same information twice in the intervention arm (once as a verbal description and once in video format) compared with once in the control arm (verbal description only). Finally, it is possible that there is a true effect of video decision aids on patients' preferences for CPR.

It is notable that only 1 of the 10 studies (by Yamada et $a l^{17}$ ) included a process through which patients could engage in deliberation or discussion with their usual healthcare provider after watching the video; despite this, few participants in this study (12\%) reported discussing the content of the video with their physician. Most notably, none of the studies in our review evaluated the impact of a video decision aid when integrated into clinical care. To have a measurable impact on downstream outcomes related to ACP, such as resource use at end of life and congruence of end-of-life care with patient wishes, we posit that video decision aids need to be embedded in a larger shared decision-making process that includes not only information exchange (the focus of the video-based interventions to date) but also engages patients in a process of deliberation with their healthcare provider and surrogate decisionmaker, and documentation of any decisions made in the medical record. ${ }^{33}$

In conclusion, there is low-to-moderate quality evidence suggesting that video decision aids may result in greater knowledge related to ACP and preferences for less aggressive care at end of life. It remains unknown whether these tools can increase congruence of end-of-life care with patient wishes. While video decision aids appear to be promising tools to assist with ACP, further evaluation, especially when integrated into clinical care, is needed before their widespread adoption into practice. 
Author affiliations

${ }^{1}$ Department of Family and Community Medicine, University of Toronto, Toronto, Ontario, Canada

${ }^{2}$ Division of Respirology, Department of Medicine, McMaster University, Hamilton, Ontario, Canada

${ }^{3}$ Department of Medicine, McMaster University, Hamilton, Ontario, Canada

${ }^{4}$ Division of Geriatric Medicine, Department of Medicine, University of Toronto, Toronto, Ontario, Canada

${ }^{5}$ Division of General Internal Medicine, Department of Medicine, McMaster University, St Joseph's Healthcare, Hamilton, Ontario, Canada

${ }^{6}$ Departments of Medicine, and Clinical Epidemiology \& Biostatistics,

McMaster University, Hamilton, Ontario, Canada

Acknowledgements The authors would like to thank Ms Neera Bhatnagar for her assistance in the design and conduct of the literature search for this systematic review, Dr Gordon Guyatt and Dr Jason Busse for their methodological advice and Dr Lawrence Mbuagbaw for biostatistical advice. Dr JJY was supported by a Research Early Career Award from Hamilton Health Sciences.

Contributors AJ and JJY conceived of and designed the study. JJY is the guarantor. AJ, KQ, SC and AG screened titles, abstracts and full-text articles for eligibility. AJ, DBV and JJY extracted data from eligible articles. SC and JJY analysed the data. All the authors participated in: interpretation of data, drafting of the manuscript and gave final approval of the version to be published, had full access to all of the data in the study, and can take responsibility for the integrity of the data and the accuracy of the data analysis.

Funding This research received no specific grant from any funding agency in the public, commercial or not-for-profit sectors.

Competing interests None declared.

Provenance and peer review Not commissioned; externally peer reviewed.

Data sharing statement The study data set is available from the corresponding author at jyou@mcmaster.ca.

Open Access This is an Open Access article distributed in accordance with the Creative Commons Attribution Non Commercial (CC BY-NC 4.0) license, which permits others to distribute, remix, adapt, build upon this work noncommercially, and license their derivative works on different terms, provided the original work is properly cited and the use is non-commercial. See: http:// creativecommons.org/licenses/by-nc/4.0/

\section{REFERENCES}

1. Silveira MJ, Kim SY, Langa KM. Advance directives and outcomes of surrogate decision making before death. $N$ Engl J Med 2010;362:1211-18.

2. Sudore RL, Fried TR. Redefining the "planning" in advance care planning: preparing for end-of-life decision making. Ann Intern Med 2010;153:256-61.

3. Detering KM, Hancock AD, Reade MC, et al. The impact of advance care planning on end of life care in elderly patients: randomised controlled trial. BMJ 2010;340:c1345.

4. Wright AA, Zhang B, Ray A, et al. Associations between end-of-life discussions, patient mental health, medical care near death, and caregiver bereavement adjustment. JAMA 2008;300:1665-73.

5. Mullick A, Martin J, Sallnow L. An introduction to advance care planning in practice. BMJ 2013;347:f6064.

6. Cook D, Rocker G, Heyland D. Enhancing the quality of end-of-life care in Canada. CMAJ 2013;185:1383-4.

7. IOM (Institute of Medicine). Dying in America: improving quality and honoring individual preferences near the end of life. Washington DC The National Academies Press, 2014.

8. Stacey D, Legare F, Col NF, et al. Decision aids for people facing health treatment or screening decisions. Cochrane Database Syst Rev 2014;1:CD001431.

9. Butler M, Ratner E, McCreedy E, et al. Decision aids for advance care planning: an overview of the state of the science. Ann Intern Med 2014;161:408-18.
10. Hostetter M, Klein S. Helping patients make better treatment choices with decision aids. Qual Matters. The Commonwealth Fund. http:// www.commonwealthfund.org/Newsletters/Quality-Matters/2012/ October-November/In-Focus.aspx (accessed 4 Feb 2014).

11. Volandes AE, Barry MJ, Chang $\mathrm{Y}$, et al. Improving decision making at the end of life with video images. Med Decis Making 2010;30:29-34.

12. Sun LH. Videos aim to inform patients about their medical options at the end of life. The Washington Post. http://www.washingtonpost. com/national/health-science/videos-aim-to-inform-patients-abouttheir-medical-options-at-the-end-of-life/2014/06/02/b0eae002-c63f11e3-8b9a-8e0977a24aeb_story.html (accessed 2 Jun 2014).

13. Heyland DK, Frank C, Groll D, et al. Understanding cardiopulmonary resuscitation decision making: perspectives of seriously ill hospitalized patients and family members. Chest 2006;130:419-28.

14. Murphy DJ, Burrows D, Santilli S, et al. The influence of the probability of survival on patients' preferences regarding cardiopulmonary resuscitation. $N$ Engl J Med 1994;330:545-9.

15. Cochrane Handbook for Systematic Reviews of Interventions Version 5.1.0 (updated March 2011). www cochrane-handbook org (serial online) 2011; The Cochrane Collaboration.

16. Guyatt $\mathrm{GH}$, Oxman $\mathrm{AD}, \mathrm{Kunz} \mathrm{R}$, et al. What is "quality of evidence" and why is it important to clinicians? BMJ 2008;336:995-8.

17. Yamada R, Galecki AT, Goold SD, et al. A multimedia intervention on cardiopulmonary resuscitation and advance directives. J Gen Intern Med 1999;14:559-63.

18. El-Jawahri A, Podgurski LM, Eichler AF, et al. Use of video to facilitate end-of-life discussions with patients with cancer: a randomized controlled trial. J Clin Oncol 2010;28:305-10.

19. Volandes AE, Paasche-Orlow MK, Mitchell SL, et al. Randomized controlled trial of a video decision support tool for cardiopulmonary resuscitation decision making in advanced cancer. J Clin Oncol 2013;31:380-6.

20. Epstein AS, Volandes AE, Chen LY, et al. A randomized controlled trial of a cardiopulmonary resuscitation video in advance care planning for progressive pancreas and hepatobiliary cancer patients. J Palliat Med 2013;16:623-31.

21. Volandes $\mathrm{AE}$, Brandeis $\mathrm{GH}$, Davis $\mathrm{AD}$, et al. $\mathrm{A}$ randomized controlled trial of a goals-of-care video for elderly patients admitted to skilled nursing facilities. J Palliat Med 2012;15:805-11.

22. Volandes AE, Paasche-Orlow MK, Barry MJ, et al. Video decision support tool for advance care planning in dementia: randomised controlled trial. BMJ 2009;338:b2159.

23. Volandes AE, Ferguson LA, Davis AD, et al. Assessing end-of-life preferences for advanced dementia in rural patients using an educational video: a randomized controlled trial. J Palliat Med 2011;14:169-77.

24. Siegert EA, Clipp EC, Mulhausen $\mathrm{P}$, et al. Impact of advance directive videotape on patient comprehension and treatment preferences. Arch Fam Med 1996;5:207-12.

25. Landry FJ, Kroenke K, Lucas C, et al. Increasing the use of advance directives in medical outpatients. J Gen Intern Med 1997;12:412-15.

26. Brown JB, Beck A, Boles M, et al. Practical methods to increase use of advance medical directives. J Gen Intern Med 1999;14:21-6.

27. O'Connor AM. Validation of a decisional conflict scale. Med Decis Making 1995;15:25-30.

28. Fried TR, Bullock K, lannone L, et al. Understanding advance care planning as a process of health behavior change. J Am Geriatr Soc 2009;57:1547-55

29. Sudore RL, Stewart AL, Knight SJ, et al. Development and validation of a questionnaire to detect behavior change in multiple advance care planning behaviors. PLOS ONE 2013;8:e72465.

30. Sudore RL, Knight SJ, McMahan RD, et al. A novel website to prepare diverse older adults for decision making and advance care planning: a pilot study. J Pain Symptom Manage 2014:47:674-86.

31. Moher D, Liberati A, Tetzlaff J, et al. Preferred reporting items for systematic reviews and meta-analyses: the PRISMA statement. Ann Intern Med 2009;151:264-9.

32. Schulz KF, Grimes DA. Allocation concealment in randomised trials: defending against deciphering. Lancet 2002;359:614-18.

33. Heyland DK, Tranmer J, Feldman-Stewart D. End-of-life decision making in the seriously ill hospitalized patient: an organizing framework and results of a preliminary study. J Palliat Care 2000;(16 Suppl):S31-9. 